International Journal of

Health, Medicine and

Nursing Practice

(IJHMNP)

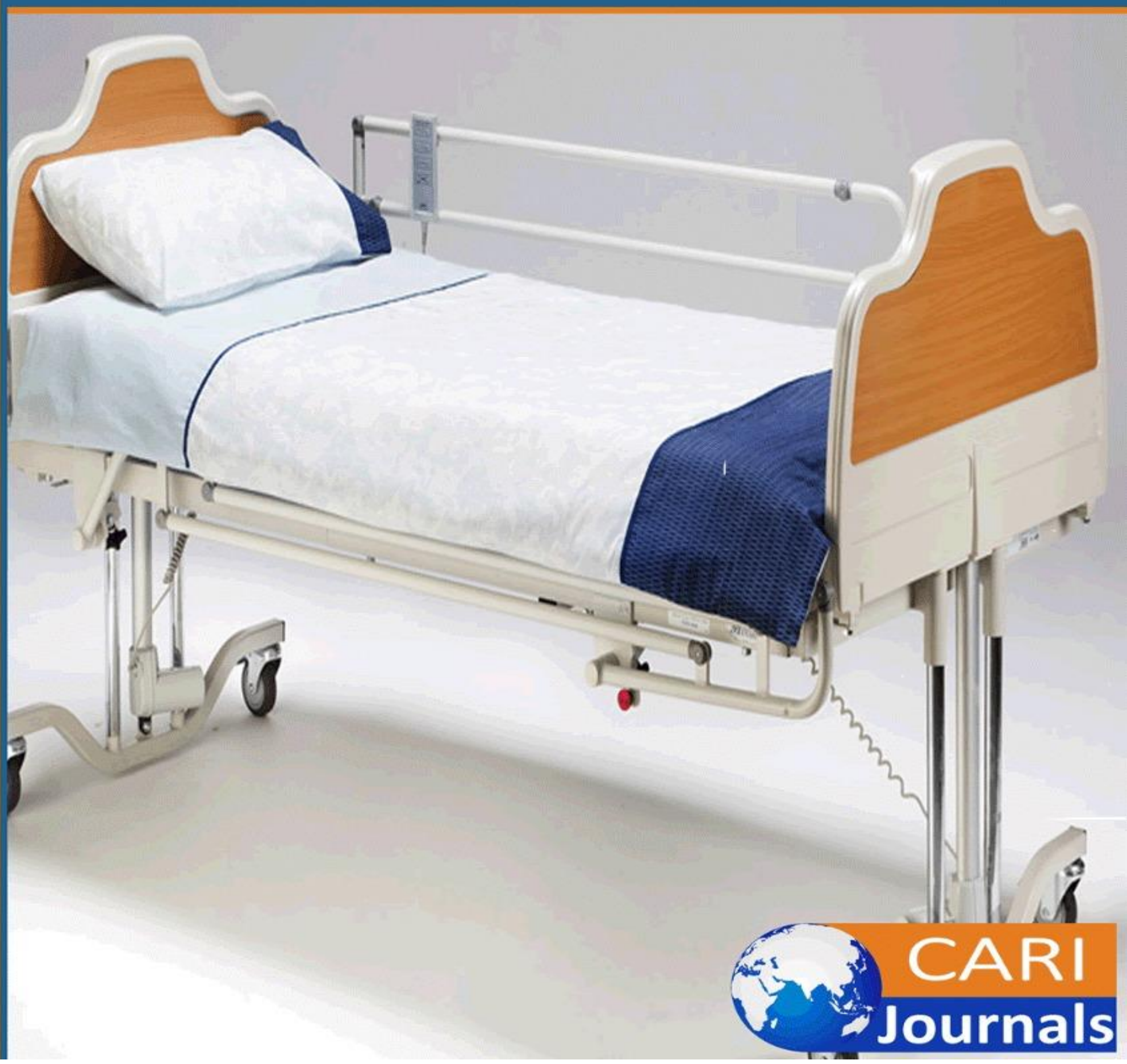




\title{
ASSESSING ATTITUDES AND PREPAREDNESS OF NURSE MANAGERS REGARDING EFFECTIVE DELEGATION IN WAPDA HOSPITAL LAHORE
}

\author{
$1 *$ Michal Nazir \\ Post RN BScN \\ Lahore School of Nursing, The University of Lahore* \\ 2*Kausar Parveen \\ Assistant professor LSN, The University of Lahore, Lahore, \\ 3*Muhammad Afzal \\ Associate professor at LSN, The University of Lahore \\ *Corresponding Author Email:michalnazir@gmail.com
}

\begin{abstract}
:
Purpose: This study aimed to identify the attitudes of registered nurses (RNs) towards delegation, their preparedness to delegate effectively, and to determine whether attitude and preparedness are related to age, experience, and education in the delegation.

Methodology: It is a quantitative research outlook in a cross- sectional descriptive design. As it is a survey of the attitudes and preparedness of effective delegation, a quantitative approach is a suitable and explicit strategy to be utilized. Data was collected with a questionnaire in Wapda hospital Lahore (N=154). Participants were 130 RNs. A self-structured questionnaire adopted from the article "Nurse Manager's Attitudes and Preparedness towards Effective Delegation in a Tertiary Care Public Hospital Lahore" with permission of the author developed by Karnested, and Haghighi. It is based on the Likert scale. It was distributed among the sample population. The questionnaire is divided into three sections. Section I; includes the demographics of the managers i.e.: age, marital status, gender, education, nursing experience. Section II; is directed towards assessment of nurse manager's attitudes consisting of 11 questions. Section III; pertains to the preparedness of nurse managers towards effective delegation and have 20 questions. The data was then analyzed on the software SPSS version 21.
\end{abstract}

Results: Most participants have a positive attitude towards delegation and identify themselves as prepared to delegate effectively. However, some of the answers indicate potential for improvement. The majority find they spend a large amount of time on jobs others could do and agree to some extent that skills of practical nurses could be better utilized through more effective delegation.

Unique contribution to theory, practice and policy: Age, experience, and former education on delegation are significantly related to a number of attitude and preparedness issues regarding confidence in delegating, mutual trust, collaboration, and communication between RNs and 
assistance personnel. Effective delegation by RNs needs to be supported by teaching, practicing and nurturing mutual trust and effective communication in nursing teams.

Keywords: Nurse Managers, effective delegation, attitudes, preparedness

\section{Background:}

Delegation is the allotment of responsibility and authority of a task to any member of the workforce to achieve a certain goal. This improves the latitude and judgement in them. (1) It is a prior existing element in clinical nursing, which has now become more significant with the increasing advancement and reforms in the profession. (2) In the 21 st century, the complexity in the responsibilities of nurses due to high expectations of the health care system has increased. Nurses, apart from their role of a caregiver, are also expected to perform other roles as being an advocate of their patients, care coordinator, educator for clients and their families, and supervisor. (3) In this crucial era, delegation is a sphere that can reduce the burden of excessive workload among nurses and thus can improve the quality of care. (4) It is a mandatory skill in the leaders of this epoch as it distinguishes managers from those who are non-managers. (5) Delegation compels the nurse managers to delegate tasks and at the same time to remain accountable for the tasks that are delegated to the delegates. (6) The manager's roles are in very diverse range including leader, caregiver, planner, controller, yet the most crucial is the delegator. As stated by the American Nurses Association and the National Council of State Boards of Nursing Joint Statement on Delegation, competencies of the modern era nursing management are that of delegating, assigning and supervising. Furthermore, the guiding and surveillance of the care are a must need to safeguard client's health and welfare, thus improving the quality of care. (7) It requires managers to be keen observer, judgmental and accountable for the deliverance of health care. The concepts of responsibility, authority and accountability must be understood by them. For instance, there is a diversity of complex situations regarding patient, in which managers are responsible in assessing the capability of other registered nurses, LPNs, and/or other assistive personnel and then delegating them the tasks to be done. This turns out in the smooth completion of work during the required time lapse and thus avoids burden and workload among them. (8)

\section{Literature review:}

From a previous study about the managers' attitudes about delegating effectively in RNs, the outcomes observed shows the score (mean) that indicates the RNs are not sure about they understand about delegation (9) Another study shows similar results i.e., seventy-four percent of the RNs attitude was neutral which implies it wasn't favorable towards delegating in an effective way (10) There was another research done to find out the extent by which managers' feel confident in order to delegate effectively, which concluded the absence of self- confidence 
in them. They must have strong character assessment and a positive attitude toward delegation to perform successful delegation (6) From a previous study, some uncertain results are observed which shows that the nurse manager's preponderance as they possess a double-edged attitude in regards to delegation and how it could be effective (11) Another important aspect of nursing task delivery is the 'preparedness' of nurse managers. It means that the nurses must accept the necessity of delegating effectively. Managers have to understand the fact that they must acquire the knowledge about delegation, the competency on their own, in order to help the other junior nurses. (2) In order to figure out the attitudes of nurse managers regarding delegation and their preparedness, another study was conducted. The findings of the study exhibit that amass of nurse managers have well known their duties legally and the fact that they are accountable in order to delegate effectively. Nonetheless, a low level of preparedness, for instance, the majority of them stated that they don't think that has adequate ability to accept the negative responses in the delegates and the delegation were observed. It is a consequence resulting in absence of confidence. Hence improvement in skills and self-assurance in managers is very important (6)

\section{Theoretical model:}

The theoretical models are a foundation that direct nurses in the provision of nursing care. There was a model developed by Joint Statement on Delegation by the ANA and NCSBN in 2006 (7), which puts the delegation process in words. This model is very useful for a nurse manager in order to direct and reassure whether the right decisions are made or not. Delegation Model Throughout the nursing profession the use of theoretical models has provided a foundation that guide the nurse in the delivery of nursing care. he principles of delegation model was proposed by ANA and has persisted since 1950. It expresses the overarching and principles related to nurse managers in the delegation process. It comprises five rights of delegation: right task, right delegation, right circumstance, right person, right direction and supervision. The delegation process is multifaceted. It begins with decisions made at the administrative level of the organization and extends to the staff responsible for delegating, overseeing the process, and performing the responsibilities. It involves effective communication, empowering staff to make decisions based on their judgment and support from all levels of the health care setting. The employer/nurse leader, individual licensed nurse, and delegate all have specific responsibilities within the delegation process. It is crucial to understand that states/jurisdictions have different laws and rules/regulations about delegation, and it is the responsibility of all licensed nurses to know what is permitted in their state NPA, rules/regulations, and policies.

\section{Operational definition:}

In this research study, manager's attitudes will be defined as positive attitude or negative 
attitude and their preparedness well be defined as well prepared or poorly prepared.

\section{Research hypothesis:}

H1: Managers will have positive attitude towards effective delegation.

HO: Managers will have negative attitude towards effective delegation.

H1: Managers will be prepared to delegate effectively.

H0: Managers will not be prepared towards effective delegation.

\section{Aims of the study:}

1. To analyze the attitudes of nurses towards delegating effectively.

2. To assess preparedness of nursing managers about effective delegation process.

\section{Significance of the study:}

This research study will first of all, assess the extent to which nurses are prepared to delegate in an effective manner and what are their attitudes towards it. It will bring about some reforms in their behaviors and will flourish their skills and competencies. If the nurse managers won't have appropriate knowledge regarding delegation, it will lead to job failure. (9) this project might be able to help to bring some upgradations in the knowledge and thus will improve their attitudes and preparedness towards effective delegation.

\section{METHODOLOGY}

\section{Setting:}

The study was executed at WAPDA Teaching Hospital Complex, Lahore. it included all in patient departments including the ORs and ERs

\section{Study design:}

It is a quantitative research in a cross- sectional descriptive correlational design. As it is a survey of the attitudes and preparedness of effective delegation, a quantitative approach is a suitable and explicit strategy to be utilized.

\section{Sample size:}

By using Cochran's (1977) formula: $\quad \mathbf{n}=\frac{z 2 p q}{d 2}$

where:

$n=$ size of sample 
$P=$ anticipated population proportion

$q=1-\mathrm{P}$

$d=$ margin of error

$z=$ confidence interval

taking,

$P=0.82$ (2)

$q=-0.17$

$d=0.06$

$z=1.96$

so, the size of the sample will be 153 .

\section{Instrument:}

A self-reporting questionnaire was distributed among the sample population. It was adopted from "the nurse managers' attitudes and preparedness among effective delegation in a tertiary care public hospital Lahore". (2) The questionnaire is divided into three sections. Section I; includes the demographics of the managers i.e.: age, marital status, gender, education, nursing experience. Section II; is directed towards assessment of nurse manager's attitudes consisting of 11 questions. Section III; pertains to the preparedness of nurse managers towards effective delegation and have 20 questions. Section II \& III are based on the Likert scale's five- points ranging from " 5 ; disagree, 4 ; moderately disagree, 3 ; unsure, 2 ; moderately agree to 1 ; agree".

\section{Results:}

Respondents were taken from WAPDA Teaching Hospital Lahore. Where total no. of respondents is 153. Table 1 Presents that there were $11.8 \%$ males and $88.2 \%$ females. Their ages were $3.9 \%$ below $25 \%, 7.8 \%$ vary between $26-30$ years, $37.3 \%$ belonging to the age group of $31-35$ years while $51 \%$ were above 35 years of age. $17 \%$ of the respondents were single, while $83 \%$ were married. $14.4 \%$ of the respondents were with nursing diploma, 9.8\% as diploma \& specialized, $43.8 \%$ were BSN/ Post RN, and $32 \%$ were MSN / MPH. The experience of the respondents from Table 1 was $4.6 \%$ between 5-10 years, $26.8 \%$ respondents had $11-15$ years, $40.5 \%$ were having $16-20$ years of experience, $28.1 \%$ of respondents of more than 20 years of experience. 
International Journal of Health, Medicine and Nursing Practice

ISSN 2710-1150 (Online)

Vol. 3, Issue No. 2, pp 36-47, 2021

WwW.carijournals.org

Table 1: Demographics

\begin{tabular}{|c|c|c|}
\hline Variables & Number (n) & $\%$ \\
\hline \multicolumn{3}{|l|}{ Gender } \\
\hline Male & 18 & 11.8 \\
\hline Female & 135 & 88.2 \\
\hline $\begin{array}{l}\text { Age } \\
\text { less than } 25 \text { years } \\
26-30 \text { years } \\
\text { 31-35 years } \\
\text { Above } 35 \text { years }\end{array}$ & $\begin{array}{c}6 \\
12 \\
57 \\
78\end{array}$ & $\begin{array}{l}3.9 \\
7.8 \\
37.3 \\
51\end{array}$ \\
\hline \multicolumn{3}{|l|}{ Marital status } \\
\hline $\begin{array}{l}\text { Single } \\
\text { Married }\end{array}$ & $\begin{array}{l}26 \\
127\end{array}$ & $\begin{array}{l}17.0 \\
83.0\end{array}$ \\
\hline \multicolumn{3}{|l|}{ Education } \\
\hline Nursing diploma & 22 & 14.4 \\
\hline Diploma and specialization & 15 & 9.8 \\
\hline BSN/ Post RN & 67 & 43.8 \\
\hline MSN/ MPH & 49 & 32.0 \\
\hline \multicolumn{3}{|l|}{ Experience } \\
\hline $5-10$ years & 7 & 4.6 \\
\hline $11-15$ years & 41 & 26.8 \\
\hline $16-20$ years & 62 & 40.5 \\
\hline Above 20 years & 43 & 28.1 \\
\hline
\end{tabular}

Some mixed responses of agreements and disagreements were found on different statements of attitude towards delegation. Table 2 elaborates the attitudes of the nurse managers towards the effective delegation where according to Likert scale 1 is agree, 2 is moderately agree, 3 is unsure, 4 is moderately disagree and 5 is disagree. $14.4 \%$ of the participants agree to the statement that they would delegate more but the job the delegated jobs are never done the way they want it to be done while $38.6 \%$ 
disagreed to the statement, while $5.2 \%$ were neutral about it. $32.7 \%$ of them stated with strong disagreement that they have no time to delegate effectively while $7.2 \%$ agree to it $10.5 \%$ remained unsure. 5.2\% agreed that delegation is not saving their time, $31.4 \%$ disagreed yet $16.3 \%$ remained unsure. The statement which stated that delegation is not done the way it should be done due to lack of inexperience was agreed by none, $9.8 \%$ disagreed to it, 36.6\% moderately agreed $39.9 \%$ moderately disagreed and $13.7 \%$ were unsure. $24.2 \%$ of the participants stated that they get upset when the job isn't done up to expectations, $4.6 \%$ disagreed and $13.7 \%$ were unsure about it. $24.8 \%$ stated with strong agreement they delegate less because they want perfection $45.8 \%$ moderately disagreed to it and 11.8 remained unsure. Around 51\% were very confident about their delegation, $1.3 \%$ were not confident and $18.3 \%$ were unsure if they can delegate effectively or not.

\section{Table 2: Attitudes towards delegation}

Table 3 demonstrates the preparedness of the nurse managers to delegate. This part of the questionnaire has an average of positive replies which shows that the nurse managers are well prepared for delegating in an effective manner. The statements that showed that managers are concerned about the staff's ability and they delegate after taking in account the skills of them shows $46.4 \%$ of agreement, $49.7 \%$ of the moderate agreement $2 \%$ of unsurely and $2 \%$ of moderate disagreement. Questions 3-5 about feedback from staff i.e., Giving and taking feedback to improve the staffs and manager's abilities have an agreements while $0 \%$ of the disagreement although $3.9 \%$, $2.6 \%$, and $8.5 \%$ moderately disagreed to it. Questions concerning managers to lose their authority and to be considered lazy by the staff for delegating their tasks to others have the following responses. $0 \%$ and $3.3 \%$ agreed to them, $9.2 \%$ and $9.8 \%$ disagreed, $44.4 \%, 45.1 \%$ moderately disagreed yet $31.4 \%$ and $29.4 \%$ were unsure. Managers are clear about when, where, why, how and by whom the task should be done with the average agreement of $40 \%$ and disagreement of zero percent and average $3.4 \%$ average of $32.7 \% .33 .5 \%$ and $35.3 \%$ of the strong About the documentation of the delegated duties, $16.3 \%$ says that the document them, $3.9 \%$ says they don't and $33.3 \%$ are unsure moreover $19.6 \%$ thinks that documentation of delegated tasks helps to understand the expectations and evaluation $28.8 \%$ are unsure and $19 \%$ moderately disagree. $45.1 \%$ of the respondents think that they have been sufficiently prepared for delegating, $3.9 \%$ moderately disagree and $4.6 \%$ of them are unsure. $26.1 \%$ of the managers' are ready to face staff's negative reactions towards their delegation, 13.8 are not ready and $20.9 \%$ are unsure about it.

Table 3: Preparedness toward delegation

\begin{tabular}{|c|c|c|c|c|c|c|c|c|c|c|c|}
\hline $\mathbf{S r}$ & Statement & \multicolumn{2}{|c|}{1} & \multicolumn{2}{|c|}{2} & \multicolumn{2}{|c|}{3} & \multicolumn{2}{|c|}{4} & \multicolumn{2}{|c|}{5} \\
\hline & & $\mathrm{N}$ & $\%$ & $\mathrm{~N}$ & $\%$ & $\mathrm{~N}$ & $\%$ & $\mathrm{~N}$ & $\%$ & $\bar{N}$ & $\%$ \\
\hline 1 & $\begin{array}{l}\text { I take into account staff 's individual skills prior } \\
\text { to }\end{array}$ & 71 & 46.4 & 76 & 49.7 & 3 & 2 & 3 & 2 & $\overline{0}$ & 0 \\
\hline
\end{tabular}


International Journal of Health, Medicine and Nursing Practice

ISSN 2710-1150 (Online)

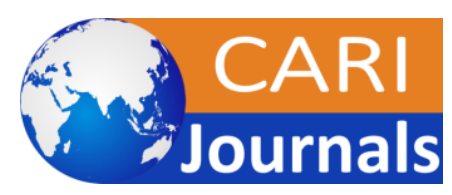

Vol. 3, Issue No. 2, pp 36-47, 2021

www.carijournals.org

\begin{tabular}{|c|c|c|c|c|c|c|c|c|c|c|c|c|c|c|}
\hline \multirow[t]{2}{*}{$\mathbf{S r}$} & \multicolumn{4}{|c|}{ Statement } & \multicolumn{2}{|c|}{1} & \multicolumn{2}{|c|}{2} & \multicolumn{2}{|c|}{3} & \multicolumn{2}{|c|}{4} & \multicolumn{2}{|c|}{5} \\
\hline & & & & & $\mathrm{N}$ & $\%$ & $\mathrm{~N}$ & $\%$ & $\mathrm{~N}$ & $\%$ & $\mathrm{~N}$ & $\%$ & $\mathrm{~N}$ & $\%$ \\
\hline 1 & \multicolumn{4}{|c|}{$\begin{array}{l}\text { I would delegate more, but the jobs I delegate never } \\
\text { seem to } \\
\text { get done the way I want them to be done }\end{array}$} & 22 & 14.4 & 23 & 15 & 8 & $\begin{array}{l}5 . \\
2\end{array}$ & 41 & 26.8 & 59 & 38.6 \\
\hline 2 & \multicolumn{4}{|c|}{ I feel that I have less time to delegate effectively } & 11 & 7.2 & 16 & 10.5 & 16 & 10.5 & 60 & 39.2 & $\mathbf{5 0}$ & 32.7 \\
\hline 3 & \multicolumn{4}{|c|}{$\begin{array}{l}\text { I get upset when the job is not done according to my } \\
\text { instructions }\end{array}$} & 37 & 24.2 & 59 & 38.6 & 21 & 13.7 & 29 & 19 & 7 & 4.6 \\
\hline 4 & \multicolumn{4}{|c|}{$\begin{array}{l}\text { I feel that staffs are not committed and the tasks } \\
\text { delegated would not be completed }\end{array}$} & 3 & 2 & 82 & 53.6 & 31 & 20.3 & 33 & 21.6 & 4 & 2.6 \\
\hline 5 & \multicolumn{4}{|c|}{$\begin{array}{l}\text { I would delegate more, but if the individual I delegate } \\
\text { the task } \\
\text { to does an incompetent job, I'll be severely criticized }\end{array}$} & 21 & 13.7 & $\begin{array}{ll}70 \\
\end{array}$ & $\begin{array}{l}5.8 \\
\end{array}$ & 34 & 22.2 & 25 & 16.3 & 3 & \begin{tabular}{|l|}
2.0 \\
\end{tabular} \\
\hline 6 & \multicolumn{4}{|c|}{$\begin{array}{l}\text { When I delegate, I usually find that often the outcome } \\
\text { is not goo } \\
\text { enough and need to re do it }\end{array}$} & 9 & 5.9 & 57 & 37.3 & 36 & 23.5 & 41 & 26.8 & 10 & 6.5 \\
\hline 7 & \multicolumn{4}{|c|}{ I find that delegation is not saving my time } & 8 & 5.2 & 54 & 35.3 & 25 & 16.3 & 48 & 31.4 & 18 & 11.8 \\
\hline 8 & \multicolumn{4}{|c|}{$\begin{array}{l}\text { Due to lack of necessary experience, I can't delegate } \\
\text { as much } \\
\text { as I want }\end{array}$} & $\mathbf{0}$ & $\mathbf{0}$ & 56 & 36.6 & 21 & 13.7 & 61 & 39.9 & 15 & 9.8 \\
\hline 9 & \multicolumn{4}{|c|}{ I delegate less because I want perfection } & 17 & 11.1 & 38 & 24.8 & 18 & 11.8 & 70 & 45.8 & 10 & 6.5 \\
\hline 10 & \multicolumn{4}{|c|}{$\begin{array}{l}\text { I can give the routine tasks, but I feel they must keep } \\
\text { the non- } \\
\text { routine out }\end{array}$} & $\mathbf{0}$ & $\mathbf{0}$ & 17 & 11.1 & 19 & 12.4 & 85 & 55.6 & 32 & 20. \\
\hline 11 & \multicolumn{4}{|c|}{$\begin{array}{l}\text { I would delegate more if I was more confident in } \\
\text { delegating }\end{array}$} & 2 & 1.3 & 17 & 11.1 & 28 & 18.3 & 78 & 51 & 28 & 18. \\
\hline & \multicolumn{4}{|c|}{ delegation } & & & & & & & & & & \\
\hline & 2 & $\begin{array}{l}\text { I give staff feedback following delegation (e.g. } \\
\text { praise) }\end{array}$ & $\mathbf{5 0}$ & 32.7 & & 96 & 62.7 & 1 & & 0.7 & 6 & 3.9 & $\overline{0}$ & $\mathbf{0}$ \\
\hline & 3 & $\begin{array}{l}\text { I seek feedback from staff on whether I have } \\
\text { explained }\end{array}$ & 51 & 33.3 & & 88 & 57.5 & 1 & & 6.5 & 4 & 2.6 & \begin{tabular}{l|l}
0 \\
\end{tabular} & 0 \\
\hline
\end{tabular}


International Journal of Health, Medicine and Nursing Practice

ISSN 2710-1150 (Online)

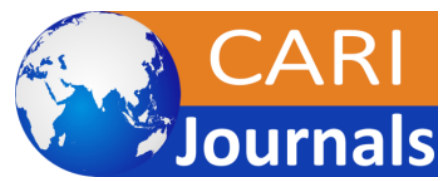

Vol. 3, Issue No. 2, pp 36-47, 2021

WwW.carijournals.org

\begin{tabular}{|c|c|c|c|c|c|c|c|c|c|c|c|}
\hline & the task sufficiently & & & & & & & & & & \\
\hline 4 & $\begin{array}{l}\text { I seek feedback from staff to improve my } \\
\text { delegation } \\
\text { skills }\end{array}$ & 54 & 35.3 & 76 & 49.7 & 10 & 6.5 & 13 & 8.5 & $\mathbf{0}$ & $\mathbf{0}$ \\
\hline 5 & I find I spend a lot of time on jobs others could do & 4 & 2.6 & 30 & 19.6 & 40 & 26.1 & 64 & 41.8 & 15 & 9.8 \\
\hline 6 & $\begin{array}{l}\text { I think I give up power or lose respect because of } \\
\text { delegation }\end{array}$ & $\mathbf{0}$ & $\mathbf{0}$ & 23 & 15 & 48 & 31.4 & 68 & 44.4 & 14 & 9.2 \\
\hline 7 & $\begin{array}{c}\text { I am concerned that staff finds me lazy for } \\
\text { delegating } \\
\text { tasks }\end{array}$ & 5 & 3.3 & 19 & 12.4 & 45 & 29.4 & 69 & 45.1 & 19 & 9.8 \\
\hline 8 & In delegation, I make clear who is to do the task & 59 & 38.6 & 89 & $\mathbf{5 8 . 2}$ & 5 & 3.3 & $\mathbf{0}$ & $\mathbf{0}$ & $\mathbf{0}$ & $\mathbf{0}$ \\
\hline 9 & In delegation, I make clear when is to do the task & 62 & 40.5 & 86 & 56.2 & 5 & 3.3 & $\mathbf{0}$ & $\mathbf{0}$ & $\mathbf{0}$ & $\mathbf{0}$ \\
\hline 10 & In delegation, I make clear where is to do the task & 64 & 41.8 & 84 & 54.9 & 5 & 3.3 & $\mathbf{0}$ & $\mathbf{0}$ & $\mathbf{0}$ & $\mathbf{0}$ \\
\hline 11 & In delegation, I make clear why is to do the task & 59 & 38.6 & 87 & $\mathbf{5 6 . 9}$ & 5 & 3.3 & 2 & 1.3 & $\mathbf{0}$ & $\mathbf{0}$ \\
\hline 12 & In delegation, I make clear how is to do the task & 57 & 37.3 & 90 & $\mathbf{5 8 . 8}$ & 6 & 3.9 & $\mathbf{0}$ & $\mathbf{0}$ & $\mathbf{0}$ & $\mathbf{0}$ \\
\hline 13 & $\begin{array}{c}\text { Nursing staff' skills could be better utilized with } \\
\text { more } \\
\text { effective delegation }\end{array}$ & 76 & 49.7 & 59 & 38.6 & 12 & 7.8 & 6 & 3.9 & $\mathbf{0}$ & $\mathbf{0}$ \\
\hline 14 & Delegated duties are documented & 25 & 16.3 & 42 & 27.5 & 51 & $\mathbf{3 3 . 3}$ & 29 & 19 & 6 & 3.9 \\
\hline 15 & $\begin{array}{c}\text { Documentation of delegated duty helps employee } \\
\text { to } \\
\text { know exactly what is expected and how the task } \\
\text { will be evaluated }\end{array}$ & 30 & 19.6 & $\mathbf{5 0}$ & 32.7 & 44 & 28.8 & 29 & 19 & $\mathbf{0}$ & $\mathbf{0}$ \\
\hline 16 & $\begin{array}{c}\text { I think I have received sufficient preparation to } \\
\text { delegate } \\
\text { through my education or at work }\end{array}$ & 69 & 45.1 & 71 & 46.4 & 12 & 4.6 & 6 & 3.9 & $\mathbf{0}$ & $\mathbf{0}$ \\
\hline 17 & $\begin{array}{l}\text { Effective delegation improves staff development } \\
\text { and satisfaction, which results in better patient } \\
\text { care and } \\
\text { patient satisfaction }\end{array}$ & 69 & 45.1 & 73 & 47.7 & 8 & 5.2 & 3 & 2.0 & & \\
\hline 18 & $\begin{array}{l}\text { I find it clear which tasks can be delegated to } \\
\text { nursing } \\
\text { staff }\end{array}$ & 64 & 41.8 & 70 & 45.8 & 12 & 7.8 & 7 & 4.6 & & \\
\hline 19 & $\begin{array}{l}\text { I think I have sufficient skills to face staff's } \\
\text { negative }\end{array}$ & 40 & 26.1 & 60 & 39.2 & 32 & 20.9 & 17 & 10.5 & 5 & 3.3 \\
\hline
\end{tabular}




\section{Discussion}

The findings of my study showed that $32.7 \%$ of them stated with strong disagreement that they have no time to delegate effectively while $7.2 \%$ agree to it $10.5 \%$ remained unsure. $5.2 \%$ agreed that delegation is not saving their time, $31.4 \%$ disagreed yet $16.3 \%$ remained unsure about it. The statement which stated that delegation is not done the way it should be done due to lack of experience was agreed by none, $9.8 \%$ disagreed to it, $36.6 \%$ moderately agreed $39.9 \%$ moderately disagreed and $13.7 \%$ were unsure. Around $51 \%$ were very confident about their delegation, $1.3 \%$ were not confident and $18.3 \%$ were unsure if they can delegate effectively or not. thus, it shows the positive attitude of nurse managers towards delegation. These findings are at odds with the result from a study where $2.7 \%$ stated with strongly disagreement that they have no time to delegate, $22 \%$ participants disagreed with this, $17.3 \%$ remained neutral, $36 \%$ agreed to the statement that they don't feel they have time to delegate and $22 \%$ strongly agreed. Where majority of the respondents agreed to the statement that they don't have much time for delegating and thus have negative attitude. On a question that any job they delegate will not be done because of the staff not commitment, $4 \%$ disagreed, $24.7 \%$ were neutral, $55.3 \%$ participants agreed to the statement, and 16\% strongly agreed that they feel lack of commitment from the nurse's subordinates. Another statement was asked I (Nurse managers) would delegate more if I (Nurse managers) were more confident in delegating 0\% Strongly disagreed, 2.7\% disagreed, 9.3\% neutral, 59.3\% agreed to this and $28.7 \%$ strongly agreed with this statement. (2) Another study indicates that there was a relatively positive attitude towards delegation among the participants. Still some responses were negative and needs improvement. If the job is not done right, it makes the nurse manager upset and unhappy. Some participants had negative attitude about others and believed that if they do a committed job with good delegation, the delegators will all times delegate themselves and will not do much of them. Participants with low experienced believed that their delegation would be improved after they are encouraged and given confidence (p.002) as against with registered nurses with more experience (10) The results of this study indicate an overall of positive preparedness among nurse managers where majority of the answers were in the agreement to the statements. In a previous study, majority of the study participants stated that they don't feel that they have sufficient skills to respond to the negative reactions of the delegates during delegation. This might be because of lack of confidence or might be because of low preparation therefore needs the development of skill and confidence among the nurse managers (6) The result findings of a previous study suggest that $78 \%$ of the emergency nurse managers stated that they were prepared and having excellent or good delegation skills. But still there were $22 \%$ such Nurse Managers who were not prepared and had low score on knowledge of delegation and basic principles of delegation. (13) In this study, $45.1 \%$ of the respondents think that they have been sufficiently prepared for delegating, $3.9 \%$ moderately disagree and $4.6 \%$ of them are unsure. $26.1 \%$ of the managers are ready to face staff's negative reactions towards their delegation, 13.8 are not ready and $20.9 \%$ are unsure about it. In a previous study, on question statement that nurse managers think they have received sufficient preparation to delegate through education or training, $0.7 \%$ strongly disagreed, $0.00 \%$ disagreed, $12.6 \%$ neutral, $20.7 \%$ agreed to the above statement and $66 \%$ strongly agreed. (2)

\section{Limitations:}


1 The total number of sample i.e. 153 is quite low for findings of massive population

2 Short time duration, that is period of 4 months

\section{Conclusion:}

Overall, the findings of this study exhibit a positive attitude of nurse managers towards effective delegation. Yet, some of the uncertainty in the responses regarding attitudes brought about the conclusion that to that in order to enhance the quality of patient care outcome, it is necessary for them to attain knowledge of delegation and the techniques to practice delegation effectively. This can only be done if delegation is added to the curriculum in the Nurse Managers additional education. Moreover, confidence-boosting activities in academic institutions must be practiced in the form of simulation-based study to enhance their ability to be confident while delegating.

\section{Recommendations:}

1 As knowledge is the only source of better delegation outcomes, nurses need to be educated well about it

2 There must be an environment of trust and confidence between nurse managers and the delegates for the progress of delegation

3 Honest assessment is the key to future successful delegation

\section{References}

1. delegation in nursing management : common errors. Bai, H.J. 2, 2014, Asian J.Nursing education and research, Vol. 4, pp. 242-244.

2. Nurse manager's attitudes and preparedness towards effective delegation in a tertiary care public hospital lahore. Khadim, Hafiza Anam. 3, 2018, Natl. J. Health sci, Vol. 3, pp. 99106.

3. Toward 2020: visions for nursing setting the stage for the future. Villeneuve M, Macdonald J. 5, 2006, Can. Nurse, Vol. 106, p. 22.

4. al., M. Sabah et. 4, 2018, Int. J. Grad. Res., Vol. 4, pp. 149-155.

5. Roussel L. Russell C, swansburg RJ. Management and leadership for Nurse administrators. Boston, USA : Jones and Bartlett publishers, 2006.

6. nurse managers attitudes and preparedness towards effective delegation in Saudi hospitals . Salem OA, Hakami AA. 2016, Health Sci. J.

7. Principles for delegation. association, American Nurses. 2011, ANA, USA. 
International Journal of Health, Medicine and Nursing Practice

ISSN 2710-1150 (Online)

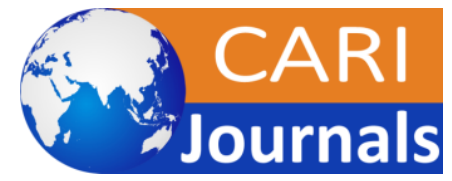

Vol. 3, Issue No. 2, pp 36-47, 2021

WwW.carijournals.org

8. delegation skills: essential to the contemporary nurse. VA, Ruff. 2011, Sophia St. Catherine University.

9. A Study of Relationship between Leader Behaviors and competencies. Malik, Sikandar Hayat. 2, Karachi : Pak. J. Commer. Soc. Sci., 2012, Vol. 6.

10. delegation of RNs revisited: Attitudes towards delegation and preparedness to delegaate effectively. Kærnested B, Bragadóttir H. 2012.

11. Nurse Managers' Attitude and cmpetency towards delegation. Roaa Sabri Gassas, Sabah Mahmoud Mahran, Hasnah Irfan Banjar. Jeddah : American Jr. of Nursing Sci., 20 
International Journal of Health, Medicine and Nursing Practice ISSN 2710-1150 (Online)

Vol. 3, Issue No. 2, pp 36-47, 2021

www.carijournals.org 